\title{
Prevention of Epineural Fibrosis in Rats by Local Administration of Mitomycin C or Daunorubicin
}

\author{
Emin VURAL ${ }^{1}$, Murat YILMAZ², Konuralp ILBAY ${ }^{3}$, Gül ILBAY ${ }^{4}$ \\ ${ }^{1}$ Derince Hospital, Department of Neurosurgery, Kocaeli, Turkey \\ ${ }^{2}$ Altinova Hospital, Department of Neurosurgery, Sakarya, Turkey \\ ${ }^{3}$ Kocaeli University, School of Medicine, Department of Neurosurgery, Kocaeli, Turkey \\ ${ }^{4}$ Kocaeli University, School of Medicine, Department of Physiology, Kocaeli, Turkey
}

\section{ABSTRACT}

AIM: Epineural adhesion after peripheral nerve surgery is common. The purpose of this study was to evaluate the macroscopic and histopathologic effects of topical mitomycin $\mathrm{C}$ and daunorubicin on epineural scar formation.

MATERIAL and METHODS: In this study, we used 15 rats (30 nerves). Two test groups and one control group were created. Sciatic nerve exposure was created bilaterally in each group (30 nerve examinations in total). In experimental group 1, cotton pads that had absorbed mitomycin $\mathrm{C}(0.5 \mathrm{mg} / \mathrm{ml})$ were placed onto the nerves for 5 minutes while in experimental group 2 , cotton pads that had absorbed daunorubicin $(0.2 \mathrm{mg} / \mathrm{ml})$ were placed onto the nerves for 5 minutes and cotton pads that had absorbed saline were applied to the control group. Eight weeks after the first surgery, surgical dissection was performed for the evaluation of neurolysis sites. Epineural adhesions were classified utilizing a numerical grading layout.

RESULTS: We did not find any adverse effect with topically applied mitomycin $\mathrm{C}$ and daunorubicin. Within the 3 groups, no significant difference was seen in skin and fascia-muscle cavity closure ( $p>0.05)$. Macroscopically, mitomycin $\mathrm{C}$ and daunorubicin decreased the adhesion of sciatic nerve to adjacent structures. There was intensive epineural scar formation in the control group. Scar tissue thickness and fibroblast/fibrocyte cell number were less in the two test groups compared with the control group ( $p<0.001)$. There was no statistical difference between the two test groups.

CONCLUSION: Epineural scar formation after peripheral nerve surgery may be reduced by using topical application of mitomycin $\mathrm{C}$ and daunorubicin.

KEYWORDS: Daunorubicin, Mitomycin C, Perineural fibrosis, Peripheral nerve, Rat, Topical

\section{INTRODUCTION}

The main reason for the failure of peripheral nerve surgery is post-operative adhesion after surgery. Intraoperative nerve injury, bleeding or a simple manipulation of the nerve can result formation of scar tissue via thickening of the epineurium. Nerve compression that is caused by postoperative scarring may result in functional impairment and pain. Strong and prolonged adhesion of nerves to adjacent structures can give rise to ischemia and further nerve injury $(22,27,33,39)$. Many surgical techniques have been developed to reduce and prevent epineural scarformation (microsurgical techniques, endoscopic techniques, nerve transposition, dermofascial fat grafts, and muscle flap) (34). Daunorubicin or daunomycin (DNR) is a chemotherapeutic agent that is a member of the anthracycline family. It is used for some types of cancer treatment. Mostly, it is used for the treatment of specific types of leukemia (acute myeloid leukemia and acute lymphocytic leukemia). Daunorubicin usage is recommended locally after pterygium surgery, glaucoma surgery and strabismus surgery due to 
findings that it inhibits the activation of fibroblast proliferation in ophthalmology $(1,5,37,38)$. Mitomycin $\mathrm{C}(\mathrm{MMC})$ is already in use primarily for anti-tumor activity of adenocarcinomas and carcinomas of the genitourinary tract, but also as a broadly used topical agent in ophthalmology for prevention of postoperative fibrosis, especially in strabismus surgery, refractive corneal surgery and trabeculectomy in glaucoma surgery $(4,26,32,36,42)$.

Previous studies have proven that MMC and DNR inhibit fibroblastic proliferation and decrease fibroblast collagen synthesis. The most important side effect of DNR is lasting and dose-dependent cardiotoxicity that is caused by free radicals. One of the most serious side effects of MMC is temporary bone marrow toxicity. At the same time, it can lead to pulmonary fibrosis and kidney damage. No serious side effects after topical application of MMC and DNR have been observed (1, 2, 5, 6, 30, 35, 37, 38). MMC and DNR were used topically in our study for anti-adhesion effects.

\section{- MATERIAL and METHODS}

This study was performed at the Experimental Medicine Research and Application Unit Laboratory (DETAB) and the Department of Pathology Laboratory with the permission of the board of ethics at the Kocaeli University. Fifteen adult male Wistar rats weighing 200-280g were used. 12-24 hour light and dark environment at room temperature was provided. The animals were fed standard rat food and tap water ad libitum. In this experimental study, rats were divided into 3 groups of 5 units. The first group was control group, the second group was the MMC applied group and the third group was the DNR applied group.

\section{Surgical Procedure}

Intramuscular ketamine hydrochloride (40 mg/kg) and xylazine $(5 \mathrm{mg} / \mathrm{kg}$ ) were used for general anesthesia in all animals. The sciatic nerves were displayed bilaterally and separated from surrounding tissues with a sterile technique; the tibial and peroneal components were clearly separated back toward the sciatic foramen. A nylon brush was used for creating abrasion injury. During this procedure the nerves were gently retracted and protected. The rats were then divided into three groups for study: the DNR applied group, the MMC applied group and the control group. In the control group (5 rats, 10 sciatic nerves), cotton pads $(10 \times 10 \mathrm{~mm})$ with saline were applied onto the nerves for $5 \mathrm{~min}$; in the MMC group (5 rats, 10 sciatic nerves), cotton pads with $\mathrm{MMC} 0.5 \mathrm{mg} / \mathrm{ml}$ were placed onto the nerves for $5 \mathrm{~min}$; in the DNR group (5 rats, 10 sciatic nerves), cotton pads with DNR $0.2 \mathrm{mg} / \mathrm{ml}$ were placed onto the nerves for $5 \mathrm{~min}$. The wounds were sutured with polyglactin suture material in each animal. No complication was seen after the application of topical MMC and DNR to rats.

\section{Evaluations}

Eight weeks after the first surgery,the neurolysis sites of the rats in the DNR-treated group, MMC-treated group and the untreated control group were evaluated by surgical dissection under deep anesthesia. Epineural adhesions were evaluated according to the the numerical grading scheme described by Petersen et al. (33) (Table I).

\section{Histological Study}

The sciatic nerve and adjacent scar tissue were removed en bloc and left in $4 \%$ neutral buffered formalin overnight. Tissues were cross-sectioned at $5 \mu \mathrm{m}$ and embedded in paraffin blocks. Hematoxylin and eosin stains were used. Masson trichrome stain was used for connective tissue evaluation. The thickness of the scar and nerve tissue were evaluated under light microscopy (Olympus BX51, Tokyo, Japan) using an ocular micrometer (Olympus), and the scar tissue formation index was obtained by dividing then thickness of the scar tissue by the thickness of the nerve tissue (31). The fibroblasts/ fibrocytes were enumerated in four different quadrants around the epineurium for each nerve, and the mean number of fibroblasts/fibrocytes was calculated and counted under $\times 40$ magnification. Each specimen was classified according to the following measure, which has been stated by several authors (10-12): Grade 1 less than 100 fibroblasts, Grade 2 100-150 fibroblasts, and Grade 3 more than 150 fibroblasts.

\section{Statistical Analysis}

Differences between the groups were evaluated by Chi-square and Mann-Whitney $U$ tests. All differences were considered significant if the "p" level was under 0.05 .

\section{- RESULTS}

\section{Clinical Evaluation}

No significant difference was found among the DNR applied, MMC applied and control groups in terms of the wound healing region and neurological function of the leg $(p>0.05)$.

Table I: Numerical Grading Scheme for Gross Evaluation Described by Petersen et al. (33)

\begin{tabular}{l|cl}
\hline Tissue & Grade & Definition \\
\hline \multirow{3}{*}{ Skin and muscle fascia } & 1 & Skin or muscle fascia entirely closed \\
\cline { 2 - 3 } & 2 & Skin or muscle fascia partially open \\
\cline { 2 - 3 } Nerve adherence and nerve separability & 3 & Skin or muscle fascia completely open \\
\cline { 2 - 3 } & 1 & No dissection or mild blunt dissection \\
\cline { 2 - 3 } & 2 & Some vigorous blunt dissection \\
\hline
\end{tabular}




\section{Anatomical Evaluation}

The skin sutures were removed after four weeks. Wound regions were evaluated at the eighth week. The control group nerves showed significantly more perineural adhesions than the MMC- and DNR-treated nerve groups (Figure 1A-C). Skin, muscle, and deep fascia closure was nearly complete according to the Petersen numerical grading scheme, $(p>0.05)$. Nerve adherence and nerve separability were significantly less in MMC and DNR-treated animals than in the control group $(p<0.0001)$. No difference was found in terms of adherence in both test groups. The results of gross evaluation of the groups are summarized in Table II.

\section{Histopathological Evaluation}

Nerves treated with saline consistently demonstrated a thick band of dense epineural connective tissue surrounding them (Figure 2A). In contrast, nerves treated with MMC and DNR were surrounded by a few thin, dark bands of connective tissue (Figure 2B, C). Quantitative evaluation of the density of the connective tissue surrounding the nerves is summarized in Table III. A statistically significant difference between the control group and the experimental groups was observed $(p<0.001)$. In the control group, the number of fibroblasts/ fibrocytes was significantly $(p<0.024, p<0.007)$ higher than in the MMC- and DNR-treated groups (Table IV).

\section{DISCUSSION}

There is no exact statistical data about the incidence of postoperative adhesion formation but it is estimated as $30 \%$. In a study conducted in the UK, the first year adhesion reoperation ratio after lower abdominal surgery was $7.2 \%(40)$. One of the most important problems encountered in peripheral nerve surgery is adhesion. This condition influences surgical success. In severe adhesions; pain, motor and sensory disorders can occur. This occurs due to tethering and/or compression of the nerves $(27,39)$. Therefore, postoperative adhesion formation is extremely important for the operation success. Various agentsx such as cis-hydroxyproline, antitransforming growth factor- $\beta$ antibody, aprotinin, human amniotic fluids, ADCON-T/N, MMC and low-dose radiation therapy have been used to prevent epineural scar formation $(9,10,16,28-31,33)$.

Adhesions are abnormal fusions between tissues and organs due to an inflammation process after surgical or non-surgical trauma $(17,25)$. This is actually a part of the normal wound healing $(7,8,13-15)$. The purpose is to achieve less dense, thin and easily separated tissue adhesions surgically. A good surgical technique attempts to treat the tissue as much as possible and prefers minimally invasive techniques to reduce the incidence of adhesions. The adhesion rate decreases if less contact with foreign substances and less manipulation can be achieved during the operation. Removal of blood is always to be preferred.
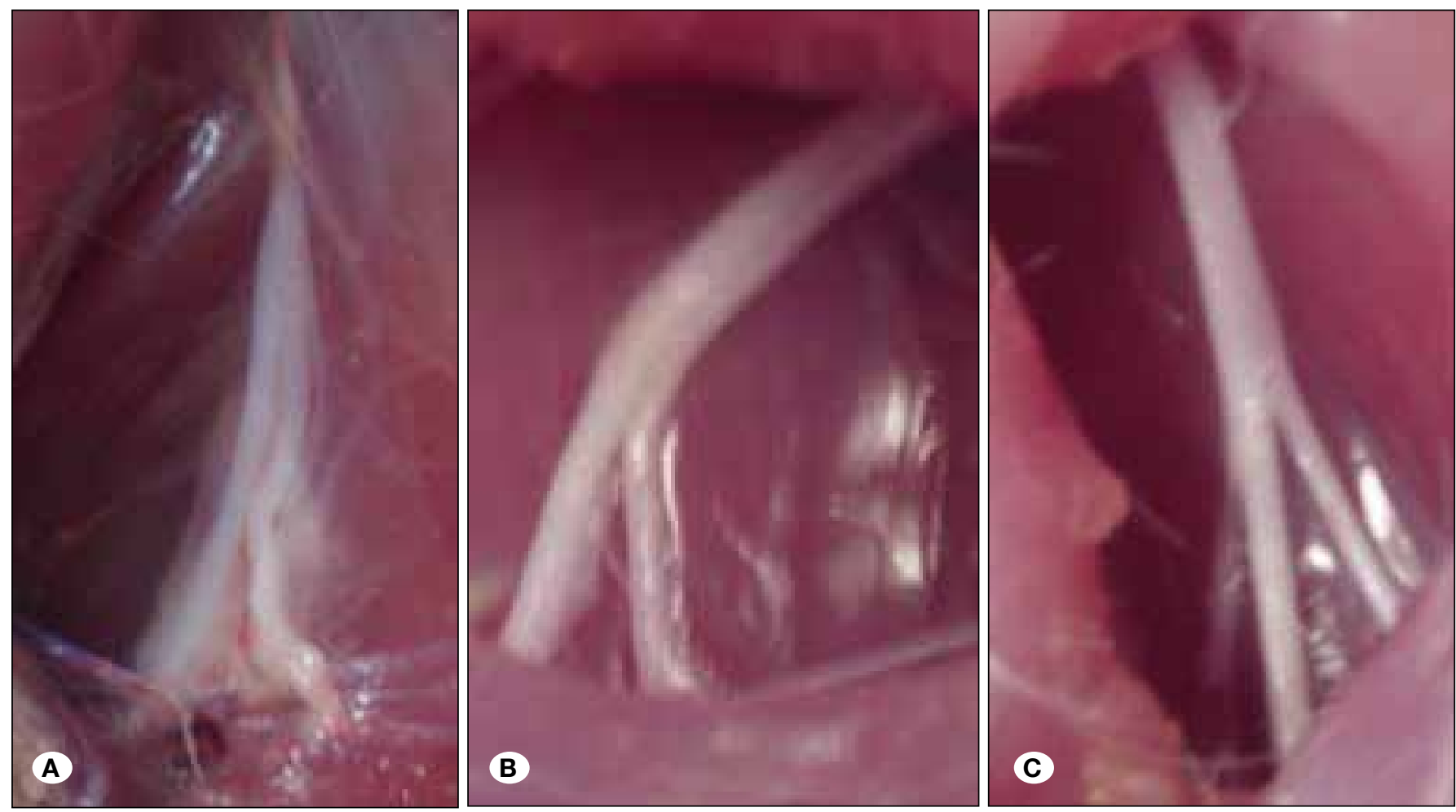

Figure 1: Photographs demonstrating the macroscopic appearance of sciatic nerves at 8 weeks post-surgery. A) Nerves treated with saline were surrounded by scarring and tethered to the surrounding tissue. B) Nerves treated with mitomycin $\mathrm{C}$ were easily dissected from the surrounding tissue, and the tibial and peroneal components were easily separated with blunt dissection. C) Nerves treated with Daunorubicin were easily dissected from the surrounding tissue. 

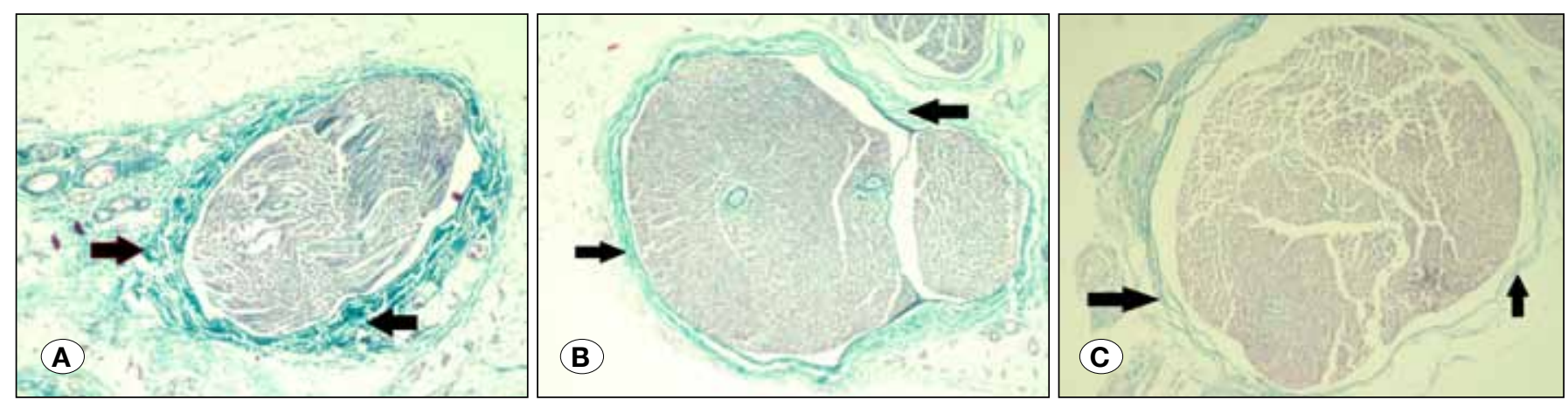

Figure 2: Photomicrographs of cross-sections of nerves and surrounding tissue. Sections were stained with Masson trichrome stain for collagen. A) Photomicrograph of tissue from a control group rat. Nerves treated with saline demonstrated a dense band of darklystained connective tissue (arrows) surrounding the sciatic nerve (original magnification, $\times 40$ ). B) Photomicrograph of tissue from a rat in the mitomycin $\mathrm{C}$ group. Nerves treated with mitomycin $\mathrm{C}$ demonstrated significantly less epineural connective tissue, composed of several thin layers (arrows) (original magnification, $\times 40$ ). C) Photomicrograph of tissue from a rat in the Daunorubicin group. Nerves treated with Daunorubicin demonstrated significantly less epineural connective tissue, composed of several thin layers (arrows) (original magnification, $\times 40)$.

Table II: Results of the Perineural Adhesion Scores

\begin{tabular}{c|ccc|ccc|ccc|ccc}
\hline & \multicolumn{3}{|c|}{ Skin closure } & \multicolumn{3}{c|}{ Muscle fascia } & \multicolumn{3}{c|}{ Nerve tissue } & \multicolumn{3}{c}{ Separability } \\
\hline Nerve no. & C & MMC & DNR & C & MMC & DNR & C & MMC & DNR & C & MMC & DNR \\
\hline 1 & 1 & 1 & 1 & 1 & 1 & 1 & 2 & 1 & 1 & 2 & 1 & 1 \\
\hline 2 & 1 & 1 & 1 & 1 & 1 & 1 & 2 & 1 & 1 & 3 & 1 & 1 \\
\hline 3 & 1 & 1 & 1 & 1 & 2 & 2 & 3 & 2 & 1 & 2 & 1 & 1 \\
\hline 4 & 1 & 1 & 1 & 1 & 2 & 1 & 2 & 1 & 2 & 2 & 1 & 1 \\
\hline 5 & 1 & 1 & 1 & 1 & 2 & 2 & 3 & 1 & 1 & 2 & 1 & 1 \\
\hline 6 & 1 & 1 & 1 & 2 & 1 & 2 & 2 & 1 & 1 & 3 & 2 & 1 \\
\hline 7 & 1 & 1 & 1 & 2 & 1 & 2 & 2 & 1 & 1 & 3 & 1 & 1 \\
\hline 8 & 1 & 1 & 1 & 2 & 2 & 1 & 3 & 2 & 1 & 3 & 1 & 1 \\
\hline 9 & 1 & 1 & 1 & 1 & 2 & 2 & 3 & 1 & 2 & 2 & 1 & 1 \\
\hline 10 & 1 & 1 & 1 & 1 & 2 & 2 & 2 & 1 & 1 & 3 & 1 & 1 \\
\hline
\end{tabular}

C: Control group, MMC: MMC-treated group, DNR: DNR-treated group.

Table III: Results of the Quantitative Histological Analysis of Perineural Scar Tissue

\begin{tabular}{cccc}
\hline Nerve no. & Control & MMC- treated & DNR-treated \\
\hline 1 & 0.300 & 0.151 & 0.142 \\
\hline 2 & 0.160 & 0.090 & 0.080 \\
\hline 3 & 0.250 & 0.102 & 0.052 \\
\hline 4 & 0.192 & 0.060 & 0.045 \\
\hline 5 & 0.200 & 0.070 & 0.053 \\
\hline 6 & 0.175 & 0.060 & 0.080 \\
\hline 7 & 0.210 & 0.040 & 0.047 \\
\hline 8 & 0.280 & 0.062 & 0.060 \\
\hline 9 & 0.230 & 0.054 & 0.028 \\
\hline 10 & 0.150 & 0.065 & 0.050 \\
\hline
\end{tabular}


Table IV: Scores of the Perineural Scar Density

\begin{tabular}{cccc}
\hline Nerve no. & Control & MMC-treated & DNR-treated \\
\hline 1 & 2 & 1 & 1 \\
\hline 2 & 2 & 1 & 1 \\
\hline 3 & 3 & 1 & 3 \\
\hline 4 & 3 & 1 & 1 \\
\hline 5 & 3 & 1 & 1 \\
\hline 6 & 1 & 1 & 2 \\
\hline 7 & 2 & 1 & 1 \\
\hline 8 & 3 & 2 & 1 \\
\hline 10 & 3 & 3 & 1 \\
\hline
\end{tabular}

A single dose of topical MMC $0.5 \mathrm{mg} / \mathrm{ml}$ or DNR $0.2 \mathrm{mg} /$ $\mathrm{ml}$ were applied to the nerves in our study. A decrease in perineural scar formation was observed with both drug applications. Skin healing and closure were complete in all three groups. Muscle cavity closure was completed in the both treatment groups. Decreased adherence of sciatic nerves to the surrounding tissue was observed in the MMC and DNR groups. There was strong epineural scarring in the control group. Nerve adherence to the surrounding tissue in the control group was significantly more prominent than in the MMC and DNR groups.

Quantitative histological evaluation of scar tissue results was consistent with the gross anatomical findings. Scar tissue density in the control group was higher compared to the groups treated with MMC and DNR. A decrease in the number of fibroblasts/fibrocytes was observed in the treatment groups.

MMC inhibits fibroblast proliferation as shown with in vitro and in vivo studies $(3,16,18-23,35,41)$. Mitomycin causes prompt inhibition of thymidine incorporation and, simultaneously, of mitosis (24). MMC is quickly and easily absorbed into cells, so that the application of an MMC-impregnated pad during surgery for just a few minutes is sufficient. MMC dose and duration of use in topical ophthalmological surgery use as well as in experimental studies varies. Doses range between 0.1 and $0.5 \mathrm{mg} / \mathrm{ml}$, and the application time range between 2 and 5 minutes (24). MMC is widely used topically in glaucoma and pterygium surgery. A recent study showed that topical application of MMC at a concentration of $0.2 \mathrm{mg} / \mathrm{ml}$ inhibits postlaminectomy peridural fibrosis in rabbits (6). There are studies showing that topical application of MMC prevents epineural fibrosis after laminectomy $(6,24)$.

Dose-related complications may occur with local and systemic applications of MMC. There are no systemic complications reported after topical application. Hypervascularisation, hematoma or necrosis may be seen due to the antiproliferative effect. No complications were observed in our study with a 0.5 $\mathrm{mg} / \mathrm{ml}$ dose and 5-minute application time.

DNR is an anthracycline antibiotic used mainly in the treatment of leukemia. It inhibits the synthesis of DNA and RNA by inhibiting the enzyme topoisomerase 11 . Thus, it effects the cell replication cycle at different points. An anti-fibroblastic effect of DNR has been shown in the field of human and animal studies, and ophthalmic surgery (37). DNR has been applied topically in strabismus surgery, pterygium surgery, and experimental and clinical vitreoretinopathy surgery. It has been shown that reproliferation decreases $(1,37,38)$. In glaucoma, its anti-fibroblastic effect has been shown both experimentally and clinically. The effective dose of DNR recommended in ophthalmic surgery is less than MMC (5).

\section{CONCLUSION}

We found no difference between the MMC and DNR groups. Application of topical MMC or DNR intraoperatively is a simple, inexpensive and useful procedure for preventing epineural fibrosis. Further studies about MMC and DNR should be conducted prior to practice in human objects.

\section{REFERENCES}

1. Atul K, Sanjeev N, Indranil C, Hem KT, Lalit KV: Role of daunorubicin in inhibiting proliferative vitreoretinopathy after retinal detachment surgery. Clin Experiment Ophthalmol 30:348-351, 2002

2. Chen CW, Huang HT, Bair JS, Lee CC: Trabeculectomy with simultaneous topical application of mitomycin-C in refractory glaucoma. J Ocul Pharmacol 6:175-182, 1990

3. Correa AJ, Reinisch L, Sanders DL, Huang S, Deriso W, Duncavage JA, Garrett CG: Inhibition of subglottic stenosis with mitomycin-C in the canine model. Ann Otol Rhinol Laryngol 108:1053-1060, 1990

4. Cruz OA: Evaluation of mitomycin to limit postoperative adhesions in strabismus surgery. J Pediatr Ophthalmol Strabismus 33:89-92, 1996

5. Dadeya S, Kamlesh MS, Fatima S: Preliminary of intraoperative daunorubicin in strabismus surgery. J Pediatr Ophthalmol Strabismus 39:340-344, 2002

6. Dogulu F, Kurt G, Emmez H, Erdem O, Memis L, Baykaner $\mathrm{K}$, Ceviker $\mathrm{N}$ : Topical mitomycin C-induced inhibition of postlaminectomy peridural fibrosis in rabbits. J Neurosurg 99:7679, 2003

7. Ellis $\mathrm{H}$ : The cause and prevention of postoperative intraperitonal adhesions. Surg Gynecol Obstet 133(3):497-511, 1971 
8. Ellis $\mathrm{H}$ : The causes and prevention of intestinal adhesions. $\mathrm{Br} \mathrm{J}$ Surg 69(5): 241-243, 1982

9. Gorgulu A, Imer M, Simsek O, Sencer A, Kutlu K, Cobanoglu S: The effect of aprotinin on extraneural scarring in peripheral nerve surgery: An experimental study. Acta Neurochir (Wien) 140:13031307, 1998

10. Gorgulu A, Uzal C, Doganay L, Imer M, Eliuz K, Cobanoglu S: The effect of low-dose external beam radiation on extraneural scarring after peripheral nerve surgery in rats. Neurosurgery 53:1389-1395, 2003

11. He Y, Revel M, Loty B: A quantitative model of postlaminectomy scar formation. Effects of a nonsteroidal antiinflammatory drug. Spine 20:557-563, 1995

12. Hinton JL Jr, Warejcka DJ, Mei Y, McLendon RE, Laurencin C, Lucas PA, Robinson JS Jr: Inhibition of epidural scar formation after lumbar laminectomy in the rat. Spine 20:564-570,1995

13. Holmdahl L, Marlier-Bannot S: The prevention of intestinal obstruction related to adhesions. Ann Chir 131(10):647, 2006

14. Holmdalh L, Risberg B: Adhesions: Prevention and complications in general surgery. Eur J Surg 163(3):169-174, 1997

15. Holmdahl L, Risberg B, Beck DE, Burns JW, Chegini N, diZerega GS: Adhesions: Pathogenesis and prevention-panel discussion and summary. Eur J Surg Suppl 577: 56-62, 1997

16. Ilbay K, Etus V, Yildiz K, Ilbay G, Ceylan S: Topical application of mitomycin $\mathrm{C}$ prevents epineural scar formation in rats. Neurosurg Rev 28(2):148-153, 2005

17. Ito T, Yeo Y, Highley CB, Bellas E, Kohane DS: Dextran-based in situ cross-linked injectable hydrogels to prevent peritoneal adhesions. Biomaterials 28(23): 3418-3426, 2007

18. Jampel HD: Effect of brief exposure to mitomycin $C$ on viability and proliferation of cultured human Tenon's capsule fibroblasts. Ophthalmology 99:1471-1476, 1992

19. Khaw PT, Doyle JW, Sherwood MB, Grierson I, Schultz G, McGorray S: Prolonged localized tissue effects from 5-minute exposures to fluorouracil and mitomycin C. Arch Ophthalmol 111:263-267, 1993

20. Khaw PT, Sherwood MB, Doyle JW, Smith MF, Grierson I, McGorray S, Schultz GS: Intraoperative and post operative treatment with 5-fluorouracil and mitomycin-c: Long term effects in vivo on subconjunctival and scleral fibroblasts. Int Ophthalmol 16:381-385, 1992

21. Khaw PT, Sherwood MB, MacKay SL, Rossi MJ, Schultz G: Fiveminute treatments with fluorouracil, floxuridine, and mitomycin have long-term effects on human Tenon's capsule fibroblasts. Arch Ophthalmol 110:1150-1154, 1992

22. Kwaan JH, Rappaport I: Postoperative brachial plexus palsy. A study on the mechanism. Arch Surg 101:612-615, 1970

23. Lee DA, Lee TC, Cortes AE, Kitada S: Effects of mithramycin, mitomycin, daunorubicin, and bleomycin on human subconjunctival fibroblast attachment and proliferation. Invest Ophthalmol Vis Sci 31:2136-2144, 1990

24. Lee JY, Stenzel W, Ebel H, Wedekind C, Ernestus RI, Klug N: Mitomycin $\mathrm{C}$ in preventing spinal epidural fibrosis in a laminectomy model in rats. J Neurosurg 100 (1Suppl Spine):52-55, 2004

25. Lucas PA: Stem cells for mesothelial repair: An understudied modality. Int J Artif Organs 30(6):550-556, 2007
26. Majmudar PA, Forstot SL, Dennis RF, Nirankari VS, Damiano RE, Brenart R, Epstein RJ: Topical mitomycin-C for subepithelial fibrosis after refractive corneal surgery. Ophthalmology 107:8994, 2000

27. McLellan DL, Swash M: Longitudinal sliding of the median nerve during movements of the upper limb. J Neurol Neurosurg Psychiatry 39:566-570, 1976

28. Nachemson AK, Lundborg G, Myrhage R, Rank F: Nerve regeneration and pharmacological suppression of the scar reaction at the suture site. An experimental study on the effect of estrogen-progesterone, methylprednisolone-acetate and cishydroxyproline in rat sciatic nerve. Scand J Plast Reconstr Surg 19:255-260, 1985

29. Nath RK, Kwon B, Mackinnon SE, Jensen JN, Reznik S, Boutros $S$ : Antibody to transforming growth factor beta reduces collagen production in injured peripheral nerve. Plast Reconstr Surg 102:1100-1106, 1998

30. Oh SY, Park DW, Chang BL: The effect of mitomycin-C on the healing process in rabbit extraocular muscle surgery. Ophthalmic Surg Lasers 30:305-309, 1999

31. Ozgenel GY, Filiz G: Effects of human amniotic fluid on peripheral nerve scarring and regeneration in rats. J Neurosurg 98:371-377, 2003

32. Palmer SS: Mitomycin as adjunct chemotherapy with trabeculectomy. Ophthalmology 98:317-321, 1991

33. Petersen J, Russell L, Andrus K, MacKinnon M, Silver J, Kliot M: Reduction of extraneural scarring by ADCON-T/N after surgical intervention. Neurosurgery 38:976-984, 1996

34. Shaw Wilgis EF: Clinical aspect of nerve gliding in the upper extremity. In: Hunter JM, Schneider LH, Mackin EJ (eds). Tendon and Nerve Surgery in the Hand. St. Louis, C.V. Mosby, Inc. 1997: 121-124

35. Spector JE, Werkhaven JA, Spector NC, Huang S, Page RN, Baranowski B, Luther M, McGehee B, Reinisch L: Preservation of function and histologic appearance in the injured glottis with topical mitomycin-C. Laryngoscope 109:1125-1129, 1999

36. Urban RC Jr, Kaufman LM: Mitomycin in the treatment of hypertrophic conjunctival scars after strabismus surgery. J Pediatr Ophthalmol Strabismus 31:96-98, 1994

37. Varma D, Sihota R, Agarwal HC: Evaluation of efficacy and safety of daunorubicin in glaucoma filtering surgery. Eye 21:784-788, 2007

38. Wiedemann P, Hilgers RD, Bauer P, Heimann K: Adjunctive daunorubicin in the of proliferative vitreoretinopathy: Results of a multicenter clinical trial. Am J Ophthalmol 126:550-559, 1998

39. Wilgis EF, Murphy R: The significance of longitudinal excursion in peripheral nerves. Hand Clin 2:761-766, 1986

40. Wilson MS, Mensiez D, Knight AD, Crowe AM: Demonstrating the clinical and cost effectiveness of adhesion reduction strategies. Colorectal Dis 4(5):355-360, 2002

41. Yamamoto T, Varani J, Soong HK, Lichter PR: Effects of 5-fluorouracil and mitomycin $\mathrm{C}$ on cultured rabbit subconjunctival fibroblasts. Ophthalmology 97:1204-1210, 1990

42. You YA, Gu YS, Fang CT, MaXQ: Long term effects of simultaneous subconjunctival and subscleral mitomycin $\mathrm{C}$ application in repeat trabeculectomy. J Glaucoma 11:110-118, 2002 